\title{
An Evolutionary Particle Swarm Optimization, EPSO, Approach to Optimize the Operation of Hydro Stations in Market Environment
}

\author{
André S. Pacheco \\ Dept. de Eng. Eletrotécnica e Computadores da FEUP \\ Porto, Portugal \\ ee06227@fe.up.pt
}

\begin{abstract}
This paper describes the application of Evolutionary Particle Swarm Optimization, EPSO, to the optimization of the short term operation of hydro stations in market environment. The maximization of the revenues of hydro stations, namely pumping stations, is gaining increasing attention by generation companies. However, this is typically a complex problem given the non linear relation between the power, the flow and the head, the temporal coupling between stations in cascade and the increasing number of pumping stations. The EPSO based algorithm displayed a very good performance in terms of the quality of the final operation plan as well as regarding the speed of convergence and the robustness of the algorithm.
\end{abstract}

Index Terms-hydro stations, EPSO, markets, optimization

\section{INTRODUCTION}

In the last twenty years the paradigm underlying the expansion and the operation planning of power systems was substantially altered in a large number of countries due to the development of electricity markets and the rapid increase of renewable and dispersed generation. Under this new more decentralized model, there are several generation companies competing to supply the demand and retailers competing to enlarge the portfolio of contracts with end consumers. Operation planning has changed with the possibility of biding to pool markets and to establish bilateral contracts.

Specifically regarding operation planning, the presence of hydro stations has always been most welcomed namely if the hydro share is significant given the revenues these assets can provide. Therefore, it is very important to develop models to select the most adequate generation/pumping periods of the planning horizon. Differently from the past, generation agents are now apparently favoring shorter term strategies that enable maximizing the profit computed as the difference between the revenues obtained from selling electricity at the market price and buying electricity for pumping in some hours along the trading period. This can be formulated as a large scale integer optimization problem namely considering cascades of hydro stations and the need to consider a trading period of at least 24 hours or more desirably of a whole week.

\author{
João Tomé Saraiva \\ Dept. de Eng. Eletrotécnica e Computadores da FEUP \\ \& INESC Porto, Porto, Portugal \\ jsaraiva@fe.up.pt
}

According to these ideas, this paper describes a short term hydro scheduling problem, HSP, on which a number of tests were run having an increasing complexity level and, as a result, an increasing applicability to real problems aiming at identifying the most adequate strategy for the operation of a set of hydro stations. This problem was initially addressed using an under relaxation approach and Genetic Algorithms $[1,2]$. In this paper, we are now using Evolutionary Particle Swarm Optimization, EPSO, to test the performance of this metaheuristic to address a realistic integer optimization problem. The paper includes results to illustrate the application of these models to plan the operation of a set of hydro stations along a planning period in order to evaluate the performance of the mentioned EPSO approach.

\section{BRIEF LITERATURE REVIEW}

The scientific community has long been interested in the optimization of the operation of hydro stations. The attention devoted to this problem is well known in countries in which hydro has a dominant position in the generation mix as in Brazil and Norway. In a large number of countries generation systems are hydrothermal which originated a large number of approaches namely to manage the use of the water on the longer term allocating a value to its use.

The original hydro scheduling problem has non linear nature and this originated the use of different non linear optimization techniques to solve it $[3,4]$. Several approximations were introduced in order to reduce the large complexity of these models namely leading to linearized models solved by commercial or customized linear packages [4]. The use of dynamic programming to solve this problem was also initially reported but the curse of dimensionality prevented its application to realistic sized systems. Other publications include binary variables as $[5,6]$ to represent the state of each station in each period. More recently, several metaheuristic techniques started to be applied to the hydro scheduling problem. These include neural networks [7], Genetic Algorithms [2, 8] and several implementations of particle swarm approaches $[9,10]$. 


\section{EVOlutionary PARTICle SWARM OPTIMIZATION, EPSO}

Particle Swarm Optimization (PSO) is a population based metaheuristic based on an analogy with swarms of birds and fish schooling. In PSO each agent is associated to a particle of the swarm and it is characterized by its position and velocity. In typical PSO approaches, a new particle is generated from an ancestor, according to the "movement rule" (1) and (2) admitting that the indices pt and it represent the particle and the iteration of the algorithm. The particle pt in iteration it +1 results from the addition of the particle in iteration it with the velocity vector. This vector (2) is the addition of three terms - the inertia related with the velocity vector of particle pt in iteration it, the memory using the position of the best of the ancestors of particle pt in previous iterations and a cooperation term that includes information from the best so far identified particle. The memory and cooperation terms are multiplied by random numbers and $\mathrm{p}$ is a communication factor that allows that only some components of the cooperation term are used to obtain the velocity vector.

$$
\begin{gathered}
X_{p t}^{i t+1}=X_{p t}^{i t}+V_{p t}^{i t+1} \\
V_{p t}^{i t+1}=V_{p t}^{i t}+\operatorname{Rnd}_{1} \cdot\left(b_{p t}-X_{p t}^{i t}\right)+\operatorname{Rnd}_{2} \cdot\left(b_{G}-X_{p t}^{i t}\right) \cdot p
\end{gathered}
$$

In these expressions $\mathrm{X}_{\mathrm{pt}}^{\mathrm{it}}, \mathrm{X}_{\mathrm{pt}}^{\mathrm{it}+1}$ are the positions of particle $\mathrm{pt}$ in iterations it and it $+1, \mathrm{v}_{\mathrm{pt}}^{\mathrm{it}}$ and $\mathrm{v}_{\mathrm{pt}}^{\mathrm{it}+1}$ are the velocity vectors of particle pt from iteration it- 1 to it and from it to it+1, $\mathrm{Rnd}_{1}$ and $\mathrm{Rnd}_{2}$ are random numbers from uniform $[0,1]$ distributions, $b_{p t}$ is the best of the ancestors of particle $p t$ and $b_{G}$ is the best particle so far identified, best global.

Several authors report that this scheme was adequate to make the swarm converge to the zone of the optimum, but it turned difficult to obtain fine convergence to the optimum final position. Therefore, [11] proposed an evolutionary approach to the PSO algorithm that evolves as follows.

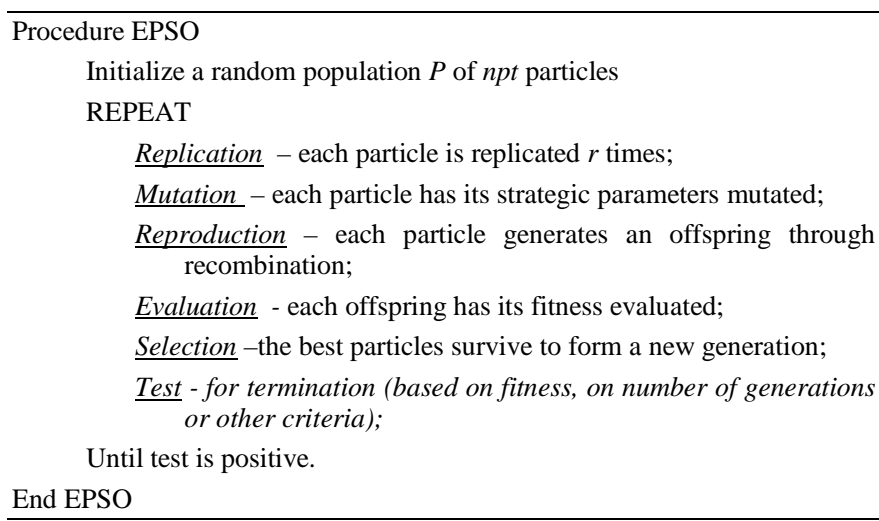

In this scheme, departing from an initial population, each particle is cloned a number of times, $r$, forming $r$ populations. Then, the weights associated to the inertia, memory and cooperation terms are mutated so that one passes from $\mathrm{W}$ to $\mathrm{W}^{*}$ using for instance an additive expression as (3) in which $\sigma$ is a learning parameters fixed externally.

$$
\mathrm{W}^{*}=\mathrm{W} \cdot[\log \mathrm{N}(0,1)]^{\tau}
$$

In the algorithm reported in [12] not only the weights of the memory, the inertia and the cooperation terms are perturbed. The EPSO algorithm includes a mutation over the best global particle identified so far, $b_{G}$, using (4). The weight $\mathrm{w}_{4}^{*}$ controls the "size" of the neighborhood of $\mathrm{b}_{\mathrm{G}}$ where it is more likely to find the real best solution. The offspring of each particle is generated by the recombination of the terms so that the velocity vector is now given by (5).

$$
\begin{gathered}
\mathrm{b}_{\mathrm{G}}^{*}=\mathrm{b}_{\mathrm{G}}+\mathrm{W}_{4}^{*} \cdot \mathrm{N}(0,1) \\
\mathrm{v}_{\mathrm{pt}}^{\mathrm{it}+1}=\mathrm{W}_{1}^{*} \cdot \mathrm{v}_{\mathrm{pt}}^{\mathrm{it}}+\mathrm{W}_{2}^{*} \cdot\left(\mathrm{b}_{\mathrm{pt}}-\mathrm{X}_{\mathrm{pt}}^{\mathrm{it}}\right)+\mathrm{W}_{3}^{*} \cdot\left(\mathrm{b}_{\mathrm{G}}^{*}-\mathrm{X}_{\mathrm{pt}}^{\mathrm{it}}\right) \cdot \mathrm{p}
\end{gathered}
$$

In this expression, $b_{\mathrm{G}}^{*}$ is the mutated best overall particle found by the swarm in their past life, $\mathrm{w}_{1}^{*}, \mathrm{w}_{2}^{*}, \mathrm{w}_{3}^{*}$ and $\mathrm{w}_{4}^{*}$ are the weights of the inertia, the memory the cooperation and the best global and $\mathrm{p}$ is a communication factor in $[0,1]$. Once the offsprings are obtained, the new particles shall be evaluated using an evaluation function that depends on the problem under analysis. Once this step is concluded, then all particles in all $\mathrm{r}$ populations are evaluated. The selection is done comparing the value of the evaluation function of particle pt of population 1, with particle pt of population 2 , .... The particle of index pt in all $r$ populations having the best evaluation function passes to the next iteration, that is, it is included in the new population. Several tests reported in [11] showed that EPSO displays faster and more accurate convergence to optimum, and it is more robust and insensitive to the initialization of weights.

\section{Mathematical Model and Solution Algorithm}

\section{A. General Mathematical Model}

When solving a Hydro Scheduling Problem (HSP) we are looking for a feasible operation schedule (inactive or operation as a generator or pump) for a set of hydro stations that maximizes the profit while enforcing a number of constraints. These stations can eventually be located in cascades so that their operation is interconnected from a temporal point of view. One of the major difficulties when addressing this problem is related with the non linear relation between the discharge volume $\mathrm{q}$, the net head $\mathrm{h}$, and the generated power $\mathrm{p}$, as illustrated in Figure 1. For each particular value of the head, there is a non linear curve relating the power with the discharge volume.

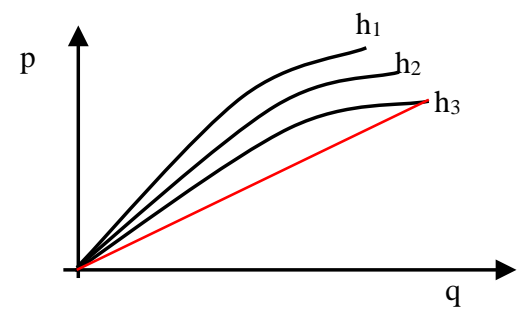

Figure 1. Family of curves for the hydropower output of a hydro power plant. 
Admitting a hydro station i being scheduled in period $\mathrm{k}$, the generated power is given by (6). In this expression, the gravity acceleration is $9,8 \mathrm{~ms}^{-2}, \mathrm{q}_{\mathrm{ik}}$ is the water flow in $\mathrm{m}^{3} \mathrm{~s}^{-1}$, $\mathrm{h}_{\mathrm{ik}}$ is the water head in $\mathrm{m}$ and $\mu_{\mathrm{T}}$ is the generation efficiency factor. As indicated above, the head has a non linear relation with the water flow originating losses in the hydro circuit. Due to these losses, the generated power is more accurately given by (7) in which $\beta$ represents the head loss coefficient. According to (7), for each value of $h_{i k}$, there is a non linear relation between $\mathrm{q}_{\mathrm{ik}}$ and $\mathrm{p}_{\mathrm{ik}}$. The head loss coefficient $\beta$ is given by (9) in which $\Delta \mathrm{hn}$ is the nominal head loss and qn is the nominal discharge flow.

$$
\begin{gathered}
\mathrm{p}_{\mathrm{ik}}=9,8 \cdot \mathrm{q}_{\mathrm{ik}} \cdot \mathrm{h}_{\mathrm{ik}} \cdot \mu_{\mathrm{T}} \\
\mathrm{p}_{\mathrm{ik}}=9,8 \cdot \mathrm{q}_{\mathrm{ik}} \cdot\left(\mathrm{h}_{\mathrm{ik}}-\beta \cdot \mathrm{q}_{\mathrm{ik}}^{2}\right) \mu_{\mathrm{T}} \\
\beta=\frac{\Delta \mathrm{hn}}{\mathrm{qn}^{2}}
\end{gathered}
$$

The literature describes different ways to deal with this non linear relation. If the head loss term in (7) is neglected, we get a linear function between the power and the flow. Doing this, the power is larger than the one given by the real curve originating larger errors in the area of large flows. This is undesirable because the current practice indicates that hydro stations tend to operate at the maximum power as most as possible. Another approximation consists of using a constant value for the head loss, corresponding to the maximum discharge flow as illustrated by the red line in Figure 1. This is a more conservative approach that is interesting since the error is small in the area of large discharge flows. The adoption of a particular approximation depends on the nature of the station. For large reservoirs, even if there are large flows, we can admit that the head barely changes and so using a constant head will not originate large errors. However, for small reservoirs larger head variation can easily occur.

If pumping is considered, the amount of power spent to pump water back to the reservoir is given by (9) where $\mu_{P}$ is the pumping efficiency factor.

$$
\mathrm{p}_{\mathrm{ik}}=9,8 \cdot \mathrm{q}_{\mathrm{ik}} \cdot\left(\mathrm{h}_{\mathrm{ik}}+\beta \cdot \mathrm{q}_{\mathrm{ik}}^{2}\right) / \mu_{\mathrm{P}}
$$

The HSP problem is formulated by (10-18) to maximize the profit (10) obtained with the operation of I hydro stations along a period of $\mathrm{K}$ hours. At each period $\mathrm{k}$ the generated power of each station $\mathrm{i}, \mathrm{P}_{\mathrm{T}_{\mathrm{ik}}}$, is sold at a market price $\pi_{\mathrm{k}}$. If station $\mathrm{i}$ is pumping then the electricity is bought at the price $\pi_{\mathrm{k}}$ thus representing a reduction of the revenue. On the other hand, if the maximum volume is exceeded then the water spill is non zero and this is penalized by the term ps.s $\mathrm{ik}_{\mathrm{ik}}$ in (10).

$$
\begin{aligned}
& \max \sum_{\mathrm{i}=1 \mathrm{k}=1}^{\mathrm{I}} \sum_{\mathrm{k}}^{\mathrm{K}}\left[\left(\pi_{\mathrm{k}} \cdot \mathrm{P}_{\mathrm{Tik}}\right)-\left(\pi_{\mathrm{k}} \cdot \mathrm{P}_{\mathrm{Pik}}\right)-\left(\mathrm{ps} \cdot \mathrm{s}_{\mathrm{ik}}\right)\right] \\
& \text { subj. } \\
& \mathrm{v}_{\mathrm{ik}}=\mathrm{v}_{\mathrm{i}(\mathrm{k}-1)}+\mathrm{a}_{\mathrm{ik}}-\mathrm{q}_{\mathrm{Tik}}-\mathrm{s}_{\mathrm{ik}}+\mathrm{q}_{\mathrm{Pik}}+ \\
& +\sum_{\mathrm{m} \in \mathrm{Mi}}\left(\mathrm{q}_{\mathrm{Tm}\left(\mathrm{k}-\phi_{\mathrm{m}}\right)}+\mathrm{s}_{\mathrm{m}\left(\mathrm{k}-\lambda_{\mathrm{m}}\right)}-\mathrm{q}_{\mathrm{Pm}\left(\mathrm{k}-\omega_{\mathrm{m}}\right)}\right)
\end{aligned}
$$

$$
\begin{aligned}
& \mathrm{vol}_{\mathrm{i}}^{1 \mathrm{~min}} \leq \mathrm{q}_{\mathrm{Tik}}+\mathrm{s}_{\mathrm{ik}}-\mathrm{q}_{\mathrm{Pik}} \leq \mathrm{vol}_{\mathrm{i}}^{1 \mathrm{max}} \\
& \mathrm{v}_{\mathrm{i}}^{\min } \leq \mathrm{v}_{\mathrm{ik}} \leq \mathrm{v}_{\mathrm{i}}^{\max } \\
& \mathrm{qT}_{\mathrm{i}}^{\min } \leq \mathrm{qT}_{\mathrm{ik}} \leq \mathrm{qT}_{\mathrm{i}}^{\max } \\
& \mathrm{qP}_{\mathrm{i}}^{\min } \leq \mathrm{qP}_{\mathrm{ik}} \leq \mathrm{qP}_{\mathrm{i}}^{\max } \\
& 0 \leq \mathrm{s}_{\mathrm{ik}} \leq \infty \\
& \mathrm{v}_{\mathrm{iK}}=\mathrm{vol}_{\mathrm{iK}} \\
& \mathrm{i}=1, \ldots, \mathrm{I} ; \mathrm{k}=1, \ldots, \mathrm{K}
\end{aligned}
$$

In this formulation:

- Mi - set of upstream reservoirs directly connected with reservoir i;

- $\mathrm{m}$ - index for a reservoir in set $M i$;

- $\mathrm{P}_{\mathrm{T}_{\mathrm{ik}}}$ - generated power of reservoir $\mathrm{i}$ at hour $\mathrm{k}$;

- $\mathrm{P}_{\mathrm{P}_{\mathrm{ik}}}$ - pumped power in reservoir $\mathrm{i}$ at hour $\mathrm{k}$;

- ps - penalty factor for spills;

$-s_{i k}-$ spill of reservoir $i$ at hour $\mathrm{k}$;

$-\mathrm{v}_{\mathrm{ik}}$-volume of reservoir $\mathrm{i}$ at hour $\mathrm{k}$;

- $\mathrm{a}_{\mathrm{ik}}$ - inflow of reservoir $\mathrm{i}$ at hour $\mathrm{k}$;

- $\mathrm{q}_{\text {Pik }}$ - pumping volume of reservoir i at hour $\mathrm{k}$;

- $\mathrm{q}_{\text {Tik }}$ - discharge volume of reservoir i at hour k;

$-\phi_{\mathrm{m}}, \omega_{\mathrm{m}}, \lambda_{m}-$ delays of turbine discharge, spill and pumping volumes;

$-\operatorname{vol}_{i}^{l \min }, \operatorname{vol}_{i}^{1 \max }$ - minimum and maximum discharge volumes of reservoir i;

$-v_{i}^{\min }, v_{i}^{\max }$ - level volume limits of reservoir $i$;

- $\mathrm{qT}_{\mathrm{i}}^{\min }, \mathrm{qT}_{\mathrm{i}}^{\max }$ - turbine discharge limits for station $\mathrm{i}$;

- $\mathrm{qP}_{\mathrm{i}}^{\mathrm{min}}, \mathrm{qP}_{\mathrm{i}}^{\mathrm{max}}$ - pumping volume limits for station $\mathrm{i}$;

- vol $_{\mathrm{iK}}$ - volume level of reservoir $\mathrm{i}$ in period, $\mathrm{K}$.

This problem includes a set of equality constraints (11), one per station $\mathrm{i}$ and per period $\mathrm{k}$, relating the volume $\mathrm{v}_{\mathrm{ik}}$ with the volume of the reservoir $i$ in the period $k-1$, with the inflow and outflow, with the water spill and with the water balance in the upstream reservoirs directly connected with it. Constraints (12) impose the minimum and maximum limits for reservoir i. Constrains (13) enforce the hourly volumes of reservoir $i$ and (14) and (15) impose limits to the water flows of station i in period k. Lastly, constraints (16) impose that water spills are non-negative and (17) sets the volume of the reservoir $\mathrm{i}$ at the end of the period, that is, at hour $\mathrm{K}$.

\section{B. Solution Algorithm Using EPSO}

In this work we used the EPSO algorithm described in Section III to solve the problem (10-18). The developed approach addresses the non linear relation between the power, the head and the discharge volume in an iterative way. At the end of one iteration, the discharged volume is obtained and it is used to update the head loss term in (7) to update the net head. This new value is then used as input in the next iteration of the EPSO algorithm. The EPSO starts with the initialization of the number of particles in the population, the 
weights in (5) and the learning parameter $\tau$ in (3). The operation state of each station in hour $\mathrm{k}$ is coded as follows:

- $\quad-1$ - the station is operating as a pump;

- $\quad 0$ - the station is not active;

- 1 - the station is operating as a generator.

This coding is based on the assumption that the generation and pumping flows are at the maximum possible, that is, if the station is generating then it is using the maximum possible flow and if it is pumping it is using the maximum pumping flow. Then, the EPSO evolves as it follows.

$\underline{\text { Step } 1}$ - Initialization - the initial population is created filling the vector that codes each particle with numbers $-1,0$ or 1 randomly sampled. Using this information, the generated or consumed powers are obtained using (7) or (9). These powers are then used to evaluate each particle using an evaluation function that includes the objective function (10) plus negative penalties if any constraint from (11) to (17) is violated. Then, the best particle corresponding to the one having the largest value of the evaluation function is store.

Repeat EPSO cycle until convergence:

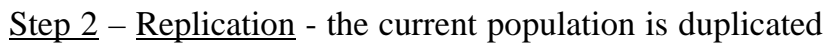
to get a cloned one;

$\underline{\text { Step } 3}$ - Mutation - using (3), the weights of the cloned population are mutated;

$\underline{\text { Step } 4}$ - Reproduction - applying (5), for each particle in both populations (initial and cloned) the offsprings are obtained. The values obtained for each cell of each particle are in general not $-1,0$ or 1 . So, any value smaller than $-0,5$ is set at -1 , and any value larger than 0,5 is set at 1. Values in the interval from $-0,5$ to 0.5 are set at 0 . This means that we are only admitting that a station is not in operation (0), or if it is generating or pumping than it is at the maximum possible value $(1$ or -1$)$.

$\underline{\text { Step } 5}$ - Evaluation - after having the operation orders for each station in each period we evaluate each offspring using the evaluation function already described in Step 1;

$\underline{\text { Step } 6}$ - Selection - for each position of the new population there are two candidate particles, one from the current population and the other from the cloned one. From this pair, it passes to the new population the one having the largest value of the evaluation function. The best particle in every position of the population is updated as well as the best global particle identified so far;

$\underline{\text { Step } 7}$ - Convergence - this cycle continues until the next condition is valid: the global best particle did not change for a pre specified number of iterations and the standard deviation of the evaluation function of the particles in the new population is smaller than a specified threshold.

\section{RESUlTS USING A CASCADE OF HYDRO STATIONS}

\section{A. Data of the test hydro system}

The hydro system used to test the developed approach includes four reservoirs with the characteristics in Table I. Table II presents the hourly prices for a period of 48 hours.
Table I. Characteristics of the four hydro stations.

\begin{tabular}{|lr|r|r|r|}
\cline { 2 - 5 } \multicolumn{1}{c|}{} & Res. 1 & Res. 2 & Res. 3 & Res. 4 \\
\hline Initial volume $\left(\mathrm{hm}^{3}\right)$ & 900 & 20 & 30 & 9 \\
\hline Final volume $\left(\mathrm{hm}^{3}\right)$ & 900 & 20 & 30 & 9 \\
\hline Minimum volume $\left(\mathrm{hm}^{3}\right)$ & 800 & 10 & 10 & 8 \\
\hline Maximum volume $\left(\mathrm{hm}^{3}\right)$ & 1000 & 30 & 50 & 10 \\
\hline $\mathrm{qT}_{\mathrm{i}}^{\max }\left(\mathrm{m}^{3} / \mathrm{s}\right)$ & 400 & 120 & 70 & 50 \\
\hline $\mathrm{qP}_{\mathrm{i}}^{\max }\left(\mathrm{m}^{3} / \mathrm{s}\right)$ & 400 & 120 & 70 & 50 \\
\hline Head $(\mathrm{m})$ & 50 & 100 & 150 & 500 \\
\hline Discharge efficiency, $\mu_{T}$ & 0,88 & 0,89 & 0,89 & 0,90 \\
\hline Pumping efficiency, $\mu_{P}$ & 0,92 & 0,93 & 0,93 & 0,93 \\
\hline
\end{tabular}

Table II. Electricity prices in $€ / M W h$ for a $48 \mathrm{~h}$ period.

\begin{tabular}{|c|c|c|c|c|c|}
\hline Hour & Price & Hour & Price & Hour & Price \\
\hline 1 & 55,00 & 17 & 58,50 & 33 & 56,15 \\
\hline 2 & 45,00 & 18 & 62,00 & 34 & 64,18 \\
\hline 3 & 46,50 & 19 & 90,60 & 35 & 70,24 \\
\hline 4 & 45,44 & 20 & 85,00 & 36 & 70,18 \\
\hline 5 & 45,52 & 21 & 85,00 & 37 & 72,63 \\
\hline 6 & 45,51 & 22 & 80,47 & 38 & 66,36 \\
\hline 7 & 45,58 & 23 & 70,00 & 39 & 59,78 \\
\hline 8 & 55,49 & 24 & 79,72 & 40 & 59,06 \\
\hline 9 & 56,16 & 25 & 56,20 & 41 & 60,64 \\
\hline 10 & 61,75 & 26 & 46,25 & 42 & 64,44 \\
\hline 11 & 72,50 & 27 & 46,02 & 43 & 91,91 \\
\hline 12 & 71,74 & 28 & 45,74 & 44 & 83,13 \\
\hline 13 & 72,42 & 29 & 45,36 & 45 & 84,49 \\
\hline 14 & 66,25 & 30 & 43,75 & 46 & 80,96 \\
\hline 15 & 61,07 & 31 & 43,89 & 47 & 67,05 \\
\hline 16 & 58,95 & 32 & 58,02 & 48 & 78,22 \\
\hline
\end{tabular}

B. Results for Test 1

Test 1 was the simplest one and it was used to set a number of parameters of the EPSO algorithm. In this test we did not consider inflows and we admitted that the four stations are independent from a hydro point of view. According to Table I, since the initial and final volumes are equal, the number of pumping and generation periods should be equal. This allowed us to more easily evaluate the convergence of the algorithm to the optimal solution and to make a number of runs that lead to select populations with 20 particles, a value of 0,9 to initialize the weights of each term in (5) and a value of 0,2 for the learning parameter $\tau$ in (3).

\section{Results for Test 2}

In this test we are now considering the following inflow:

- $\quad$ Station $1-100 \mathrm{~m}^{3} / \mathrm{s}$ for hours 1, 2, 3 and 4;

- Station $2-50 \mathrm{~m}^{3} / \mathrm{s}$ in all hours;

- $\quad$ Station 3 - $100 \mathrm{~m}^{3} / \mathrm{s}$ for hours $14,15,16,17$ and 18 ;

- $\quad$ Station 4 - no inflows.

This test also includes the computation of the head loss term in (7) and (9) calculated with the values obtained for $\mathrm{q}_{\mathrm{ik}}$ in the previous iteration. Figure 2 displays the operation orders for each of the 4 stations along 48 hours. Because inflows are now considered, the number of discharge and pumping periods are no longer equal. In fact, there should be more discharges than pumping periods since the inflows help filling the reservoirs of stations 1,2 and 3 with water again. Regarding Station 4, the operation strategy is not changed 
regarding Test 1 because Station 4 has no inflows. The presence of inflows and the reduction of the number of pumping periods strongly contribute to increase the final profit given by (10).
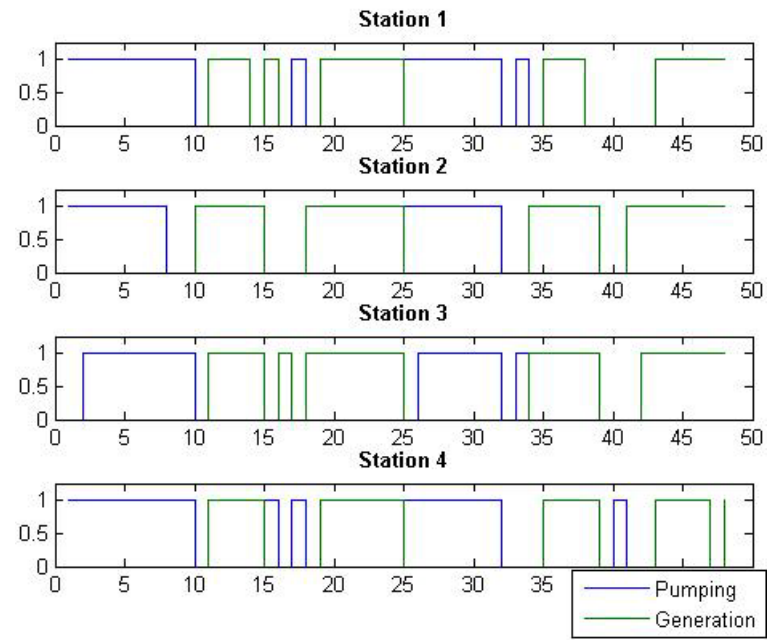

Figure 2. Generation and pumping periods for each station.

\section{Results for Test 3}

Test 3 differs from Test 2 because we are now planning the operation of the 4 stations for an entire week that is for 168 hours. In this case, the number of pumping orders for Stations 1, 2 and 3 is smaller than the number of generation orders and generation tends to occur when the electricity prices are larger. On the other hand, since Station 4 has no inflows the number of generation and pumping orders are equal so that the final ad initial volumes are equal.

\section{E. Results for Test 4}

In Test 4 we admit that Stations 1 and 2 are in cascade (Station 1 upstream Station 2) while Stations 3 and 4 remain independent. We are also assuming that both inflows and the head loss term in (7) and (9) are considered. Figure 3 displays the operation orders for a period of 24 hours.

Station 1
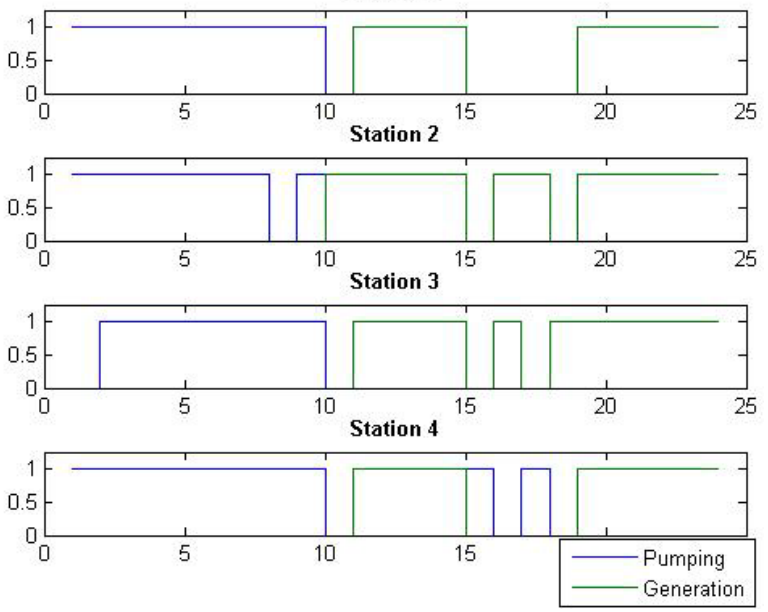

Figure 3. Generation and pumping periods of the four stations.

The operation orders for Stations 3 and 4 are unchanged but the number of pumping periods of Station 2 is now much more reduced. This is because Station 2 is downstream
Station 1 and so it is receiving water whenever Station 1 is generating. As a result of this cascade, the number of pumping periods of Station 2 is more reduced because this station can more easily meet the equality of the initial and final volumes using the water coming from Station 1.

\section{CONCLUSIONS}

This paper described the use of an Evolutionary Particle Swarm Optimization, EPSO, algorithm to the optimization of a set of hydro stations. The adequate planning of the operation of hydro stations (including generation and pumping periods) has always been a matter of concern to generation companies. With the advent of electricity markets this issue gained new attention because of the need of generation companies to optimize the use of their generation assets considering market prices. With this paper and with the MSc Thesis on which it is based we hope to have contributed with a further step in the development of powerful tools that help generation companies in optimizing the operation of their portfolios.

\section{ACKNOWLEDGEMENT}

The first author thanks EDP Gestão da Produção SA, namely Eng. Virgílio Mendes and Eng. José Carlos Sousa for guidance during the preparation of the MSc Thesis and for providing the data of the hydro system.

\section{REFERENCES}

[1] J. C. Sousa, V. T. Mendes, J. T. Saraiva, "Estimation of the Remuneration of Hydro Plants in a Market Environment Using an Iterative Under-Relaxation Approach", in Proceedings of the 2009 IEEE Bucharest Power Tech, Bucharest, Romenia, 28 June - 2 July 2009.

[2] G. S. Sampaio, J. T. Saraiva, J. C. Sousa, V. T. Mendes, "Optimization of the Operation of Hydro Stations in Market Environment Using Genetic Algorithms", in Proceedings of the European Electricity Market Conference, EEM'13, Stockholm, May 2013.

[3] S. J. P. Mariano, J. P. Catalão, V. M. F. Mendes, L. A. M. Ferreira, "Profit-Based Short-Term Hydr Scheduling Considering HeadDependent Power Generation", in Proceedings of the 2007 IEEE Lausanne Power Tech, pp. 1362 - 1367, July 2007.

[4] H. Pousinho,V. Mendes, J. P. Catalão, "Profit-Based Head-Dependent Short-Term Hydro Scheduling Considering Risk Constraints", in Proceedings 2011 IEEE Trondheim Power Tech, pp. 1-6, June 2011.

[5] A. Borghetti, C. D'Ambrosio, A. Lodi, S. Martello, "A MILP Approach for Short-Term Hydro Scheduling and Unit Commitment with HeadDependent Reservoir", IEEE Transactions on Power Systems, vol. 23, no. 3 , pp. $1115-1124$, August 2008

[6] J. Garcia-Gonzalez, G. A. Castro, "Short-Term Hydro Scheduling with Cascaded and Head-Dependent Reservoirs Based on Mixed Integer Linear Programming", in Proceedings of 2001 IEEE Porto Power Tech, Porto, Portugal, September 2001.

[7] R. Naresh, J. Sharma, "Hydro System Scheduling Using ANN Approach", IEEE Transactions on Power Systems, vol. 15, no. 1, pp. 388 - 395, February 2000.

[8] P. T. Leite, A. F. M. Carneiro, A. L. F. Carvalho, "Energetic Operation Planning Using Genetic Algorithms", IEEE Transaction on Power Systems, vol. 17, no. 1, pp. 173 - 179, February 2002.

[9]C. Samudi, G. P. Das, P. C. Ojha, T. S. Sreeni, S. Cherian, "Hydrothermal Scheduling Using Particle Swarm Optimization", in Proceedings of the IEEE 2008 T\&D Conference and Exposition, Chicago, April 2008.

[10]L. Bin, R. Jun, "Application of Simulated Annealing Particle Swarm Algorithm in Optimal Scheduling of Hydropower Plant", in Proceedings of the Int. Conf. on Artificial Intelligence and Computational Intelligence, vol. 4, pp. 608 - 610, Shanghai, November 2009.

[11] V. Miranda, H. Keko, A. Jararillo, "Stochastic Star Communication Topology in Evolutionary Particle Swarms (EPSO)", Int. Journal of Computational Intelligence Research, vol. 4, pp. 105-116, 2008. 